\title{
Training Evaluation in an Organization using Kirkpatrick Model: A Case Study of PIA
}

\author{
Mehwish Rafiq \\ Department of Management Sciences, SZABIST, 90 and 100 Clifton, Karachi 75600, Pakistan
}

\begin{abstract}
The purpose of this study is to evaluate the training effectiveness on PIA by applying the four levels Kirkpatrick model consisting of reaction, learning, behavior \& Results. This study is cross sectional, primary data was collected through interviews from different batches representing different levels of the Kirkpatrick model. Effectiveness of training at the different levels was being evaluated through construct/theme developed on the basis of literature review. For level one evaluation interviews were conducted from employees who had recently completed their training; for level 2,3\&4 the respondents, who had completed same training about 3 months, 6 months and year earlier respectively. The results indicated that reaction of the participants were positive for training except duration was too short, secondly they have applied skills \& knowledge which they had learnt from training. A positive consequence of the training is that most of the participants got promoted from their current designation with the improvement in their pay scales. Thus, the soft skills trainings were effective with the participants desiring more opportunities to attend soft skills training session at least quarterly basis, to further improve their skills and enhance their knowledge. This model is rarely used in Pakistan, specially in PIA it is used first time by the help of this research study and find effectiveness of training.
\end{abstract}

Keywords: Training Evaluation, Kirkpatrick Model, PIA training Center, Training

\section{INTRODUCTION \\ 1.1 Background}

According to Vemic (2007), With advent of external environment's fierce competition, complexity in work and innovative technology breakthrough, and uncertainty of turbulent society, training needs become common in almost all organization whether public or private. There is a gap between knowledge provided in formal schooling and required in business organization. In order to fill this gap training is required. Knowledge is really a reliable source to deal within turbulent, uncertain and complex global environment. Knowledge provides competitive advantage. Complex business challenges have to be answered easily with special and selective knowledge gathered during training. This is the reason almost all companies are paying more attention to training.

Sanders (2011), has presented a new point of view of training, according to him, previously training was considered to be an expenditure, but now it is serve a role of an investment activity. For better result organization should invest in improving hard \& soft both type of skills. In addition to this Karen, (1996) stated that training is an ongoing process. And planning put effectiveness in training, along with this participant's selection, administrative support, venue, moderator/facilitator, and contents of training.

Byrne (1999), agrees with Janzeb and Bashir (2012), that now a days organizations follows a modernization. To cope with this, organization need employees with updated skills \& knowledge, and this can be done through training and development.

In addition to Aguinis and Kraiger (2009), have the same opinion that organization not run in isolation or not only face local challenges but they work with different multinational organization, and these multinational bring global competitive culture and environment which affects the local economy and operating business entities. He also stated that training \& development not only improves the individual capabilities or skills but also whole team and overall organization. Training advances the individual skill which help in improving his performance in an organization as a result organizations effectiveness improves in society or in general. Thus training of employee definitely play key role in enlightening the organization performance, well-being, profitability in a society. Individual training results organization's effectiveness.

\subsection{Training and Development}

Training and development is for improving, enhancing and updating the skill, knowledge \& abilities to perform better. As challenges of external environment increases day by day which ultimately affect the internal customers as well (Niazi, 2011).

Training means equipping employees with new or traditional methods or techniques or modules to translate information, knowledge \& skills to practice it in an organization to improve overall effectiveness of organization. Training is for current stage and development is for future stage (Silvia, 1999). Training \& development is a part of prime objective of an organization. In some organization learning culture is their social responsibility. From various study it has been found that there is a link between organizational performance and 
training \& development. Training \& development has strategic contribution in organizational goal (Niazi, 2011). On the other hand Silvia (1999), stated that training play a vital role by contributing to the nation's human capital.

\subsection{HRM and Training \& Development}

It is also important function of human resource management. As it help organization to enhance the knowledge, skills \& abilities of their employees. As business outside world is rapidly changing, challenges of outside environment are become fierce. Many organizations spent millions of dollars in the world to equip their workforce to cope with rapidly changing out side challenges. This program is to facilitate the employee to accelerate or enhance the skills of their employee, so that they can understand the job competencies. All training design, need analysis, implementation \& evaluation has done by HR department. As HR is the policy maker, they design policy for betterment of company's performance, and now training has become one of the part of HR policy. Because it direct contributes to the employee performance, which leads to overall organizational performance (Adralin, 2004).

In addition to this Jahanzeb and Bashir (2013), identified that training \& development directly contributing to employee's career development. Organization focus on key position's career development but according to him organization must emphasizes on fresh employee for their high ranking position in future, so that against organization's this effort guaranteed loyalty, commitment, sincerity with the same organization. This is not written agreement but rather emotional \& psychological commitment. In order to tackle with financially competitive \& dominant market. As business environment is continuously fluctuating due to haphazardly changes taste, preferences, life style, more advance needs, in order to embark upon these condition organization must have competent and well equipped employees. This equipment of talent material and skills is incorporated in employees through training programs.

\subsection{Pre-Training Need Assessment State}

According to Aguinis and Kraiger (2009), for appropriate goal setting, better design and delivery of training need assessment is very important. Theoretical training need assessment is also required. There are tools available for validation of training need assessment. Pre-training need assessment is very much effective for training results. Training need analysis done on the basis of three aspects: organizational analysis, what are the organizational goals should be met through training program? Personal analyses, who are the people, should be trained for particular training? \& task analyses, what job task should be effectively perform as a result of training (Edens and Bell, 2003). Analysis of training needs is to be done for training program specification. For example which particular skills need to improve what methodology will be adopted, who will be the participants. This data is very important for preparing a effective training design (Edralin, 2004). It is also useful in training design $\&$ evaluation stage. In training needs analysis the objectives are set. Such as what job standards to be met after this training program? What levels of performance are required from trainees at the end of this training program. These objectives are arises on need analysis stage and evaluation also done to meet these need. Thus overall research objective are need vs. outcome of training.

\subsection{Training As An Ongoing Process}

The success of business is depending on well trained employees. In order to expend the business organizations gives continue training to their employee to be fully equipped. (Arguis and Kraiger, 2009). As challenges of external environment is not constant which required regular interval updated knowledge (Niazi, 2011). Providing continuous training to employees' results creativity \& innovation. It is the best source for the organization to become a differentiated organization from others. Usually organizations spend $2 \%$ to $3 \%$ for employee learning $\&$ development from their annual revenue. The competitive advantage is the result of innovation done by organization with the help of their employee, and these innovations as a result of knowledge. Upgraded knowledge leads to continuous innovation. (Vemic, 2007). The most effective training is an ongoing training workshops. A series of workshops is the key to well-trained the employee (Edralin, 2004)

\subsection{Importance of Training}

According to Adralin (2004), training help to enhance organizational commitment, it improve employee job performance, it help to cope with internal and external challenges, employee morale also enhances, knowledge and skills also upgraded, efficient work environment, employee's problem solving skills also develop, they able to acquire technical skills to use machinery, tools, problem solving skills, it also build confidence in employee personality. Due to that many organizations spend lots of money for training. Training now has become strategic training, as it is serving long term strategic organizational goal. 


\subsection{About Pakistan International Airlines}

When the vision of Pakistan existence seemed to be real. Mr. Jinnah has before formation of Pakistan in June 1946 had realized that for two separate wings of 1100 miles distance, their would be a need for efficient transportation mode imperative. He asked Mr. Ispahani top industrialist for nation's own airline setup on priority. Pakistan's first airline was born on $23^{\text {rd }}$ October 1946 with the name of orient airways ltd. It has initiated from culcutta. It has started its operations with BOAC aircraft. With the passage of time orient airways had transferred to Pakistan after formation of Pakistan. An orient airway was private company with limited resources. In order to grow, in 1955 it has been merged with Pakistan government to expend its operation and become new state owned airline with the name of PIAC. Thus it became the greatest asset of nation.

In 1955, it had sent its first international flight. It had earned foreign exchanged which was utilized for its further expansion \& growth. First chairman of PIA was Mr. Ispahani, and Zafar-ul-Ahsan was first MD. Then in 1959, Nur khan air commander was appointed as a MD of PIA. With his great leadership vision in short span of time he represented PIA on of the best world Airline. PIA had broken the record of fastest airline in the world from Karachi to London in aprox.6 hours, which is remain till to date. Asghar Khan in his 3 year tenure gives new lively life to PIA with some glamorous changes in PIA. Such as, he had design the new uniform of airhostesses from French designer. In 1961, they had developed their own in house training center with the name of ground training school. Now this building become PIA dispensary and PIA training center moved other building near head office. In 1967, PIA maintained his first historic data in IBM1404. In 1970s PIA had setup their own flight kitchen, which provided food to other airlines as well. Recently, in 2008 PIA got the certification clearance for air safety from CAA-ANO. They had opened their engine shop at head office.

\subsection{Research Problem}

As there is a fierce competition, complexity in market and external environment become more \& more turbulent and unprecedented changes takes place. (Vemic, 2007) Due to that job contents continuously upgrade but employee skill remain same until unless it could be polish through training \& development (Govil S.K. \& Usha $\mathrm{K}$., 2014). There is a need to bridging the gap between knowledge acquired from school and current business frequent change requirement knowledge \& skills (Vemic, 2007). In order to fulfill this gap employee training is become necessary which leads to team and organization effectiveness. Due to this reason organizations focus on training \& development of employees which ultimately results in organization's success. Previously training was considered to be expenditure, but now it is serve a role of an investment activity (Sanders, 2011). Effectiveness of training depends, by which criteria evaluation of training has been done. Evaluation program is as essential as training program conduct in an organization. Because it ensure that by the end of training program employees knowledge upgraded and developed (Topno H., 2012).

\subsection{Purpose of the Research}

The purpose of this research study is to evaluate the training effectiveness on Pakistan international airlines by applying the four levels Kirkpatrick model consisting of reaction, learning, behavior \& Results.

\subsection{Research Questions}

- Q.1 How effective is the training imparted by PIA Training Center?

- Q.2 How Kirkpatrick model is being evaluated the objective of training at each level of Kirkpatrick Model in the context of PIA Training Center?

\subsection{Research Objectives 1.11.1 Main Objective}

- The objective of this study is to evaluate the effectiveness of training at Pakistan International Airlines by using 4 levels Kirkpatrick model.

\subsubsection{Sub-Objectives}

- $\quad$ To evaluate the effectiveness of first level (Reaction) of Kirkpatrick model at PIA.

- $\quad$ To evaluate the effectiveness of second level (Learning) of Kirkpatrick model at PIA.

- $\quad$ To evaluate the effectiveness of third level (Behavioral change) of Kirkpatrick model at PIA.

- To evaluate the effectiveness of fourth level (Results) of Kirkpatrick model at PIA.

\subsection{Limitations \& Delimitation}

Although Kirkpatrick model usually requires a time series approach with each of four levels, following in a phased manner. With the first level (reaction) of evaluation taking place immediate after the completion of training. This is followed by second level (learning) a gap of 1-3 month after the first level or 3-6 months after the training session undertaken. The third level (behavioral or attitudinal changes) of evaluation is required to 
take place after 6-9 months or later after the training work shop and the final level (results) is being evaluated about a year after training or more. However a time constrain this study is cross sectional, primary data was gathered through interviews conducted from different batches representing different levels of the Kirkpatrick model, i.e for the level one evaluation interviews were conducted from employees who had recently completed their training; similarly, for level 2,3,\&4 the respondent, who had completed same training (soft skills training) about 3 months, 6 months and year earlier respectively.

This study will not cover the training need analysis process, and not directly measure the moderator/facilitators influence on training, this will also not cover the training budget and cost analysis process.

This research will not analyze the analysis of training methods, modules \& models comparison, and their impact on employee. This model will not include the Philips fifth step of training evaluation that is return on investment.

\section{LITRATURE REVIEW}

\subsection{What is training?}

An organization consist of social group of people working together to achieve common organizational goal. In addition to this they cumulatively to share their norms, value belief system with each other. Organization's management assigns different roles and give them responsibilities to each individual based on skills and knowledge they have, they fit them into different functions and give them specific position. But with the passage of the time they need to upgrade the existing positions, but in order to perform this task management review the job contents \& persons specifications. As higher the position, higher the job skills knowledge. Sometimes existing task review which required upgraded knowledge and skills. As employee get older for a particular position, their experience riches their knowledge and enhances the skills to perform. But these knowledge gained by spending lots of time for particular task. (Govil and Usha, 2014).

According to Govil and Usha (2014), outside world is challenges are very rapid which requires upgraded knowledge and enhanced skills. The ultimate and short time effective solution for this problem is learning \& development. Training is a systematic approach to add skills and increases knowledge effectively in a short period. Training is design according to competency required for particular job task. It help to advance the performance, improve productivity, increase capacity and develop ability to learn.

Whenever a new employee hire in an organization he or she need to give training for his or her job. Without training one can perform on trial and error basis. Training is help to develop attitude of employee, a special attitude is required to perform certain job. Due to training many big blunder of the job task has been removed (Govil and Usha, 2014).

\subsection{PIA Training Center}

In in 1960s all training were conducted in hotel midway house, Karachi. In after 1960s, PIA had developed their own in house training center with the name of ground training school. Initial all training were conducted in Tshaped building. Now this building become PIA dispensary and PIA training center moved other building near head office. It is well established, provides all type of airline's industry related training. All local even some international air lines get training from PTC. They have very advanced infra-structure in their training center which is with approval of national \& international regulatory authorities for e.g IATA, CAA \& ICAO. Contents of the training design experts' instructors and training team according to the objective of the training. Material provided during training is handouts, presentation slides, some web side links etc. They have multiple methods for training. it depends on type of training, period \& participants of training. Such as class room lecture based, group discussion, presentation, role play exercise. Practical training, test retest, observation, experiment, case study video, audio, computer based training they have highly qualified \& specialist instructors. Their instructors are well trained, and highly knowledgeable. They have well equipped training center. Centrally air-conditioned, 3 story building. They have simulated aircraft, engine, Training equipment are very advanced \& latest. Pilots, cabin crew, engineer, flight stewards, sales personal, airport staff, head office staff. PTC was developed in vision for technical training which was the main focus of PIA. Hard skills training are mandatory for aviation employees. Without this training they unable to perform their duty. In addition to this, in 2013 PIA management has realized that there is a need for soft skills training. to develop the professional attitude of the employees. Thus, PIA has two type of training which are following.

\subsubsection{Soft Skills Training}

Soft skills are those which is for developing the professional attitude in employees. It helps employees to groom their overall personality. To help them make rational decision, to perform their duty with ethics, to help them to communicate effectively and build confidence them. Which is gradually become compulsory for all employees for their up-gradation in their job. These for senior, middle \& junior management. Some soft skills which are identified by PIA management. Training expert have identified separate soft skills for senior management \& separate for junior management these are following. 


\subsection{Historical Perspective}

According to Eden and Bell (2003), over 30 years, cumulatively 6 studies have been taken place on training and development literature. "Initially Campbel, 1971; then Stein 1980; followed by Waxley 1984; Latham then in 1988; then Tannenbaum \& Yakli 1992; finally Sales \& Cannon Bowers, 2001.

\subsection{Training Evaluation Criteria}

Edens and Bell (2003), stated that before evaluation, evaluation criteria must be decide, because for better effectiveness of training evaluation criteria is essential part. Many evaluation models have been developed but the most popular model is Kirkpatrick model. Effectiveness of what? Reaction of trainees, knowledge enhancement of knowledge, behavioral changes of trainees or overall effectiveness of overall organization. For behavior change as a result of training, knowledge is necessary but not essential pre requisite. Behavior can also change as result of training directly. Or it can say that training evaluation of level 2 can directly apply. Behavior evaluation can also do on job application of training program. For behavioral changes, take supervisor feedback and employee actual job performance after training. Sometime results on actual job can be valid because, it is also found that organizations training taking place just for formality or to implement the policy criteria but they do not get the chance for implementing the training learning.

\subsection{Literature Research}

For this study, review the research articles from 1996 to 2014. From these articles it has been found that post training period has started form 1960. From that period till now there have been lots of advancement in the training design, and training methodologies. The research on training has been become more comprehensive and more sophistical statistical approaches have been applied. Mostly studies were conducted quantitatively. Allencompassing researches have been conducted on training evaluation to find out the training effectiveness (Edens and Bell, 2003).

\subsection{Inclusion Criteria}

Number of article found related to training will be read, as the scope of this paper was training evaluation with the help of Kirkpatrick model. Firstly paper some papers read \& analyze purely related to training, secondly choice of research article review related to training evaluation and effectiveness, more emphasis on Kirkpatrick model's evaluation. For giving richness in literature review a meta-analysis and literature review based article has been included. Thirdly, the training evaluation techniques or methodology based article emphasizes. Fourthly training design related articles also review, lastly applied training researches also review for checking the out of the results, training evaluation manual and book presented by Donald Kirkpatrick has been review for better understanding. Agency based training program \& department's articlehas also been considered (Edens and Bell, 2003).

\subsection{Training Evaluation}

It is systematic approach to collect the all relevant information. This information is judgmental and descriptive. On the basis of this information one can make decision for existence of training department, who will be next participants, what method will be used to perform this training program. Training \& development is also healthy for taking an intervention in an organization. Training evaluation is useful for determining the benefits of training for employee \& organization. All trainings require the evaluation because without training evaluation no one can justify the happening of it. The justification for its investment is output of training results, such as evaluation of the program, its effectiveness on the organization. Training evaluation is not an easy task, it requires time, efforts, money. But evaluation is not only necessary for justification of investment but also to make improvement in the for the future training program. The evaluation help to find out that whether objective of the training met or not? (Mohammed and Alias).

This the method of social science, to collect the data, analyze the data, followed by interpretation, and finally communicate the relevant information regarding effectiveness of the program (MoSDMED, 2003).

\subsection{Training Effectiveness}

Training evaluation is used for finding the training effectiveness. Training effectiveness is to know about the characteristics of organization, training program itself and individuals, before training, during training, and after training. There is a difference training evaluation $\&$ training effectiveness. Training effectiveness emphasizes on macro analysis of training overall system where as training evaluation only emphasize on micro perspective of training results (ASTD, 2009).

Plameta, Myers, Gyarmati and Voyer (2011), evaluation does not means that whether training program works in an organization but also which training program best suited to the particular needs and which employees should be nominated for it under particular circumstances. The extent to which the interaction 
between design and delivery and employee capabilities and needs the more effectiveness it has. In absence of training evaluation, no one can reached to the outcome level that whether objective have been achieved or not or was training program successful or not? Without evaluation it not possible to justify the investment in training program (UN HABITAT 2012). In addition to this, effectiveness doing the right thing. It Is the cyclical process and effectiveness is a part of efficiency. Evaluation is best way to find out the effectiveness. It is a continuous process, it finds out the purpose

\subsection{Role of training in organizational performance/effectiveness.}

Training is required total commitment of the organization. Carr (2002), stated that there is no fix training evaluation method but it depends on the ultimate goal of training program and objective of particular training session. Basically there are two purpose of training first knowledge gain or practically implement. He said that training assessment best done on individual level. The main objective of the training is change in status in terms of knowledge and skills to perform task \& duties.

Edens and Bell (2003), agrees that to increase productivity of the employee, training is one the best practice. Effectiveness of training depends, by which criteria evaluation of training has been done. Kirkpatrick added that planning is itself given satisfaction of effectiveness of training program. Evaluation is necessary, because it identifies that which contents of training has become obsolete and which are new contents need to be added. According to him there are three main reasons to evaluate training program, first for improving the future program, secondly to identify the reason to continue or drop the training program and last but not least to justify the training budget and also existence of the department. Training evaluation is the systematic approach to collect the information about the outcomes of training program for future continuation of training program. This program consisted of three different steps such as planning the program, implementation and evaluation of the training program. There are five steps of training evaluation program which starts from purpose of evaluation which is followed by evaluation method, design, data collection and finally analyzing results and presented in the forms reports to show the results (Projects on Improvement of Local Administration in Columbia).

On contrary Topno (2012), stated that training is as important as other organizational activity. It requires money, time \& energy. It contributes to develop successor, employee development for future uncertain task and internal promotions. Evaluation program is as essential as training program conduct in an organization. Because it ensure that by the end of training program employees knowledge upgraded and developed.

\subsection{Training Evaluation in PIA}

At PIA training is being evaluated at the end of training session. There are number of methods used in PIA training center for evaluating training. such as individual or group presentation, MCQS based in house test to check the knowledge by external body such as NTS, MCQS based in house reaction test about training, practical test, experimental test etc. On training evaluation results they gradually improved the training methods, design, $\&$ contents. They do not used any model to evaluate the training. with multiple interviews of training director, it has been identified that they evaluate reaction and knowledge of employees and also check the skills after a sometime passed after training for promotion, and also result. On the basis of results they modified their policies, improve training program. Thus indirectly used Kirkpatrick model. As by interview and discussion it has been analyzed they used all level of Kirkpatrick model but not cumulatively or in series but separately with not phased manner, even not analyze as a model but individually.

\subsection{Issues Concerning Training in Organization}

Aguinis and Kraiger (2009), have the opinion that organization not run in isolation or not only face local challenges but they work with different multinational organization, and these multinational bring global competitive culture and environment which affects the local economy and operating business entities. He also stated that training \& development not only improves the individual capabilities or skills but also whole team and overall organization. Training advances the individual skill which help in improving his performance in an organization as result organizations effectiveness improves in society or in general. Thus training of employee definitely play key role in enlightening the organization performance, well-being, profitability in a society. Individual training results organizations effectiveness.

\subsection{Key Evaluations Issues}

There are number of issues related to training evaluation that is the evaluation program relevant to objectives of the training. At what extent, the design of evaluation is effective. The cost effectiveness is very important for evaluation due to high cost usually organization not prefer to do evaluation. It must follow the guidelines \& policy, procedure to be effective. Ultimately impact of the output justifies the effectiveness. It should be sustainable otherwise effectiveness of training program may suffer (Evaluating Learning). 


\subsection{Training Design}

Training design is the central part of the overall training program. It starts with reviewing goal of the organization, that which part of the goal requires expertise or new skill and knowledge that become the objective of the training design. Over all training session depend on training design and overall training design based on objective need to be achieved at the end of the training session (Edralin, 2004). The training design start with why and on what area should be covered in training along with physical setting such as time venue, audience, physical equipment, trainer, training contents, training evaluation Etc (Evaluating Learning).

\subsection{Conceptual Framework}

\subsubsection{Training Evaluation Methods/Models}

There are so many methods $\&$ technique to evaluate the effectiveness of training or learning, nearly all methods fall under kirkpatric/Philips models, the model consist of five different evaluation level. First four levels such as evaluation of reaction of participants who have been gone through training process, second how much learning achieved during training session, third what change has taken place in the behavior due to particular training, fourth what business result derived from training, developed by Donald L. Kirkpatrick 1976 "author of Evaluating Training Program", and fifth level such as ROI, developed by Jack Philips "author of Human Resource Scorecard". In addition to this another training evaluation technique is "Brinkerhoff Success Case Method" by Robet O. (ASTD 2009).

Bates R. (2004), presented the critical analysis of Kirkpatrick's Model, according to him initially the model was developed in 1959 to identify the likeness and not likeness of training program by participants and also at what extent participants like the training program, thus reaction of participants about training program. The reason of popularity of the model its systematic procedure, and understanding the needs of the trainers. The language and contents are very much clear, such as this model simply the complexity the program. Through this model evaluation can be done after immediately training session has been done. Through program prior evaluation of training program, not required. It is focus, contributes to the organization effectiveness, and includes less number of variables.

It is human capital, who makes the business successful or lead to failure, so it is the responsibility of the organization that they should equip their employees with updated knowledge \& skills for achieving ultimate goal of the organization because each human being has potential capability but with the passage of time rapidly changing environment their skills \& knowledge become obsolete. So in order to be market competent and respond to external challenges, organization provides sufficient $\&$ relevant training for their career development for their on organization. And without its evaluation it is not possible to justify investment and or ensure the effectiveness of training program.

\subsubsection{Training Evaluation Model}

\subsubsection{Kirkpatrick Model}

As much discussion has already taken place about this model. Further put more light on it. This model consists of four sequential steps.

a. Reaction: this is all about emotions/feelings of learner. This phase measure the effective of training program of employee' attitude \& perception. It is all about feeling of trainees for training program. Thus, it is likness \& dislikness of trainees. This criteria is for training effectiveness is suitable, when there is applied training program (Edens and Bell, 2003). The reaction of training is evaluated on the basis of objective met or not, relevancy of contents of the training, material provided during training, method used by trainer, influence of other participants, and finally overall reaction trainees. This phase or level of training is evaluated immediate after training session or within one month after training session.

b. Learning: what knowledge they get as result of training. It measures all about outcome of learning, but not measures the outcomes of job performance. The method for measuring this level's effectiveness is through "paper pencil-Test". It is not the pre-requisite criteria for behavioral effectiveness or change (Edens and Bell, 2003). In addition to this, Carr (2002), said knowledge level reviews the set objectives of the training, and checked whether learning of employees take place. The reaction of training evaluate initially by the objective of the training, how much knowledge enhanced after training or how much learning has been taken place, after training how effectively employee used knowledge learnt after training, back support for application of knowledge, relevant contents of the training, trainees expectation from training program, output for overall session. This level of training evaluation of Kirkpatrick model is being evaluated after three months of training program. The construct for this level are knowledge learning, knowledge application, organizational back support, relevancy of content, improvement, objective and employee expectation.

c. Behavior: what attitudinal changes taken place in the personality of participants. This means that what skills have been developed as a result of learning during training session. This is more closely to practical approach effectiveness. Such as, this can measure the performance on job. There one can actually identify the transference of training results. It is also measure by taking interview or opinion of immediate supervisor of trainee about his 
or her job performance after training program (Edens and Bell, 2003). The themes for evaluating this level are skills development, skills application, organizational back support, improvement \& results.

d. Results: how it is helpful in achieving organizational goal. The contribution of training program in organization's success (Justice, 2011). It is usually identified with utility analysis. Through this method dollar value can be calculated increase after training program (Edens and Bell, 2003). Training results evaluation has been evaluated delegates skill or knowledge enhancement for an organization, the knowledge and skills they able to use to performing their duty, organizational support required by delegate to apply knowledge or skills, at the end what are the improvements in results due to training. Training objective met or not, organization's expectation fulfill or not due to training.

\subsubsection{Popularity of the Model}

Bates identified five reasons for polarity of this model, firstly the model was very simple and systematic to implement. It is very clear and consists of four sequential steps. Secondly, this model perfectly fit to evaluate the objectives of the training. This can help out to divide the objective of the training among four evaluation steps and check the effectiveness of it. Thirdly, it ensures the sponsors for profit orientation, as their money was not wasted, the output or results has identified. Fourth, this model help to simply the very complex training program, that is due to this model at the end of the training session whole program has summarized. This shows the match and gap between the objective and outcome of the program. Last but not least through this model there is no need for pre training evaluation, or any evaluation during overall training session. Through this model evaluation done just overall training session completed. It is one sided that solely based on outcomes. So the trainees output or feedback is very important for the session (Bates).

\subsubsection{Limitations of the Model}

According bates, there are number of limitations of this model. Firstly, this model is incomplete, as it find out the result of existing factors and it is not work on new factors. Secondly, it is based on sequential or causal linkage model. This means that every next steps/level enhance the results of training effectiveness or it can say that one steps cause by other. Such if employees got good reaction from training which results more knowledge they gain, which is followed by positive behavioral change, ultimately results over all organizational effectiveness. From this limitation it can say that is based on positivism. Thirdly, it based on the assumption of incremental effects, such first level give less results as compare to second level give more information as compare to first level but less than third level, and so on. As some training program sponsored by stakeholders/sponsors, and employees are their own work force, in these training program companies usually shows the positive results of their training program which is ethically wrong.

\section{RESEARCH METHODOLOGY}

\subsection{Research Design}

The philosophy of this research is post-positivist. This research has tested the Kirkpatrick model of training evaluation on Pakistan internal airline. This is exploratory in nature. This is cross sectional research study has conducted on same training content (soft skills training) on different participants representing different level of Kirkpatrick model. This study has focused on four levels of Kirkpatrick model such as reaction of participants, learning after training, behavior or attitude change of employee as result of training, and finally training helpful in achieving the organizational goal. All levels have been found out through one on one in-depth interview. At a time there were two training session taking place, each group consist of 20-30 participants. For the level one evaluation interviews were conducted from these recent batches, they have recently completed their training. For level two the respondent, who had completed same training (soft skills training) about 3 months before, for level 3 , interview were conducted from the respondent who had gone through training session before 6 months and for the fourth level, interview has taken from their immediate supervisor, policy maker, trainer, etc. for the training which was conducted a year earlier.

\section{ANALYSIS, FINDINGS \& DISCUSSION}

At PIA training is being evaluated at the end of training session. There are number of methods used by PIA training center for evaluating training program. Such as individual or group presentation, MCQS based in house test to check the knowledge by external body such as NTS, MCQS based in house reaction test about training, practical test, experimental test or some time be interview if required etc. On the basis of results they modified their policies, improve training program, proposed new training programs. PIA training center has very well equipped training center, a proper and effective evaluation is still a big dilemma to justify the effectiveness of training and cost in involve in training.

As per requirement of qualitative data, analysis and data collection was taking place simultaneously. This data analyzation has stared with transcription of data during interview. After transcription of data coding has been done on hard copy transcripted document. After transcription, sorting of data has done in soft copy which is followed by sifting. This is basic coding which was done for typology and taxonomy analysis. This is 
kind of open and axial coding respectively. The coding sorting \& sifting are kind of homework which is placed in appendix for reference basis. All coding, sorting and sifting has done for typology. Prior themes have been created for data collection which was used in typology for analysis. Typology has followed by taxonomy, for that main construct has already been developed for interview protocol. Interview data has been organized and indulge in a typology in axial coding.

As this research is cross sectional and participants are from different batches for each level but the same contents, so the effectiveness of each level is find out separately.

\subsection{Level 1 Effectiveness}

In order to bring effectiveness in training program, the main objective for this soft skills training was set as promotion of employees on successfully completing the training program. From the in-depth interview it has been identified that soft skills training purpose was successful. The content of the training were very effective, almost $70 \%$ were very closely relevant to the job contents of the all participants. Each training used combination of two three methods. Thus, almost all training method were being utilized during training program. Mostly participants like the role play exercise, lecture, and interactive session. Trainer also were expert, good in knowledge, highly qualified such as masters, and graduates, with gold medalist from IBA, NUST, LUMS, NED etc universities. The collaboration among other participants were very good as the batch were mixed of employees such as different designation, department, location, age group, experience. Over all session were perfect but the weakness of the this training were long hours a day and complete duration were one week which is very short as per the content design for the training. Moreover, employees still want to continue to attend these session at least quarterly basis.

\subsection{Level 2 Effectiveness}

With in-depth interviews it has been find out that knowledge of the participants enhanced and their learning curve has increased. Even they are using this knowledge in their professional and personal life as well. Their confidence level has enhanced to use the learning which they have learnt from training program. For utilizing the knowledge they usually need immediate supervisor or manager support, and these support them getting with full enthusiasm. Most of the skills are part of their routine life according to the level of management they fall in. such as in junior management communication skills, personality grooming, ethics, team work; for middle management attitude, staffing, stress management, problem solving and for senior management leadership, decision making and negotiation skills. Their performance has improved, they are being appreciated by their immediate supervisor and most of them got promoted as a result of successfully completing training. Their efficiency increase, willingness to work enhanced, their productivity has increased. Employees want to attend more training session on monthly basis otherwise at least quarterly basis.

\subsection{Level 3 Effectiveness}

From this training, employees' attitude and behavior changed and it is showing in their performance. Their inner self specialties came out, their confidence level increased, their skills got polished. Employees are utilizing their soft skills in their daily life to work effectively and efficiently. For example, with communication skills one of the employees delighted the passenger at airport to solve the problem and provide better solution. Their way of talk and professional behavior was the reason for that success which is as result of training. Similarly some employees had taken office stationary at home for personal use but ethical skills they have learnt that this is wrong and they practically avoid this act. They try to be happy at work place and do not super impose their personal biases at work place.

\subsection{Level 4 Effectiveness}

The above three levels results have been justified by this forth level, as in this level interview has been taken from custodian, initiator and authoritarian of the training program and immediate supervisor. On their observation the delegates' knowledge and skills has developed, they have seen a great change in the behavior of the employees. The overall productivity and efficiency of employees and their willingness towards work have been increased. They said that when ever the provide any assignment all relevant supports also provided in advance but for some or rare support which is not in their hand, they unable to provide. But after this training their subordinates' productivity is improving. They suggested that like these training sessions are very important for the organization success and to change the mindset of the employees and management. There must some short training work shop be taken place at least in a month and long training work shops should be taken place quarterly basis. Thus, over all training session was very good and it need more advancement and more training should be taken place. This training is not a complete bucket but it is a continuous process. This must be going on and on.

Thus, the overall training was excellent it improves the results and met the objectives. They have some 
more training projects in hand. Which they want to implement in near future as on success on the existing courses.

\section{Conclusion}

Thus, it can say that training has a greater impact on PIA employees. Employees learning have been taken place; their skills have developed, polished \& updated. They can confidently apply the skills and utilized the knowledge as a result of training. Moreover, overall objective of the training were met. By analyzing each level individually it can say that training were effective at each level. All employees want to attend more training session, short courses every month or long complete session at least quarterly basis. The drawback of the session were long hours day made them exhausted and overall session duration were too short as per contents design for the training. Except this shortcoming, overall training sessions were excellent. All employees like the training session and their expectation for new learning were met. For the success and growth of the organization training is very fruitful. It helps to change the rigid mindset of employees and change the perspective of the overall organization. In order to make the training more effective a proper evaluation is essential. Training evaluation give the direction to the training department for move a head and make them on right track. Proper evaluation programs save the time and unnecessary cost for future trainings.

\section{References}

Aguinis H. \& Kraiger K. (2009). Benefits of Training \& Development for Individuals and Teams, Organization and Society. Annual Review of Psychology is online at Psych.anualreviews.org.

American Society for Training \& Development (2009). The Value of Evaluation: Making Training Evaluation More Effective.

Bates R. (2004). A Critical Analysis of Evaluation Practice: The Kirkpatrick Model and the Principle of Beneficence. Evaluation and program Planning, 27, 341-347.

Byrne S.M. (1999). The Value of Human Resource Development to an Organization: Providing Technical Assistant to Small Manufacturing Companies. Dissertation Submitted to the faculty of the Virginia Polytechnic Institute and State University in Partial Fulfillment of the Requirement of Degree.

Carr W. F. (2002). Designing Effective Training Evaluation Process.

Edens P.S. \& Bell S.T. (2003). Effectiveness of Training in Organizations: A Meta Analysis of Design and Evaluation Feature. Journal of Applied Psychology, 88(2), 234-245.

Jehanzeb K. \& Bashir N. A (2013). Training \& Development Program and its Benefits to Employee and Organization: A Conceptual Study. European Journal of Business and Management, 5(2).

K. Govil S. \& Usha K. (2014). The Importance of Training in an Organization. Advances in Management, 7(1).

Karen K (1996). What is Effective Training? IHRM Human Rights NGO Capacity Building Programme-Iraq.

Kirkpatrick D.L. \& Kirkpatrick J.D. Evaluating Training Program, $4^{\text {th }}$ Ed. Published by Berrett Koehler Publishers.

Niazi A.S. (2011). Training \& Development Strategy and Its Role in Organizational Performance. Journal of Public Administration and Governance, 1(2), 2161-7104.

Plameta B., Myers K., Gyarmati D. \& Voyer J.P. (2011). Understanding Training Program Effectiveness: A Comprehensive Framework Learning and Active Employment Programs project. Social Research Demonstration Corpration.

Project on Improvement of Local Administration in Cambodia. Manual on Training Evaluation.

Sanders T. (2011). Hotel Front Office Training: Turning Expenses Into Investment. University of Neveda Las Vegas, Thesis/Dissertation/Professional Paper Capstone, 7-1.

Silva S.D. (1997). Developing the Training Role of an Employer's Organization. International Labor Organization ACT/EMP Publication.

Topno H. (2012). Evaluation of Training \& Development: An analysis of Various Training Models. Journal of Business Management, 5(2), 16-22.

United Nation Human Settlement Program (UN-HABITAT) (2012). Manual on Training Need Assessment and Training Outcome Evaluation in an Urban Context.

Vemic J. (2007). Employee Training and Development and the Learning Otganization. Facta Universitatis Series: Economics and Organization, 4(2), 209-216. 
The IISTE is a pioneer in the Open-Access hosting service and academic event management. The aim of the firm is Accelerating Global Knowledge Sharing.

More information about the firm can be found on the homepage:

http://www.iiste.org

\section{CALL FOR JOURNAL PAPERS}

There are more than 30 peer-reviewed academic journals hosted under the hosting platform.

Prospective authors of journals can find the submission instruction on the following page: http://www.iiste.org/journals/ All the journals articles are available online to the readers all over the world without financial, legal, or technical barriers other than those inseparable from gaining access to the internet itself. Paper version of the journals is also available upon request of readers and authors.

\section{MORE RESOURCES}

Book publication information: http://www.iiste.org/book/

Academic conference: http://www.iiste.org/conference/upcoming-conferences-call-for-paper/

\section{IISTE Knowledge Sharing Partners}

EBSCO, Index Copernicus, Ulrich's Periodicals Directory, JournalTOCS, PKP Open Archives Harvester, Bielefeld Academic Search Engine, Elektronische Zeitschriftenbibliothek EZB, Open J-Gate, OCLC WorldCat, Universe Digtial Library, NewJour, Google Scholar

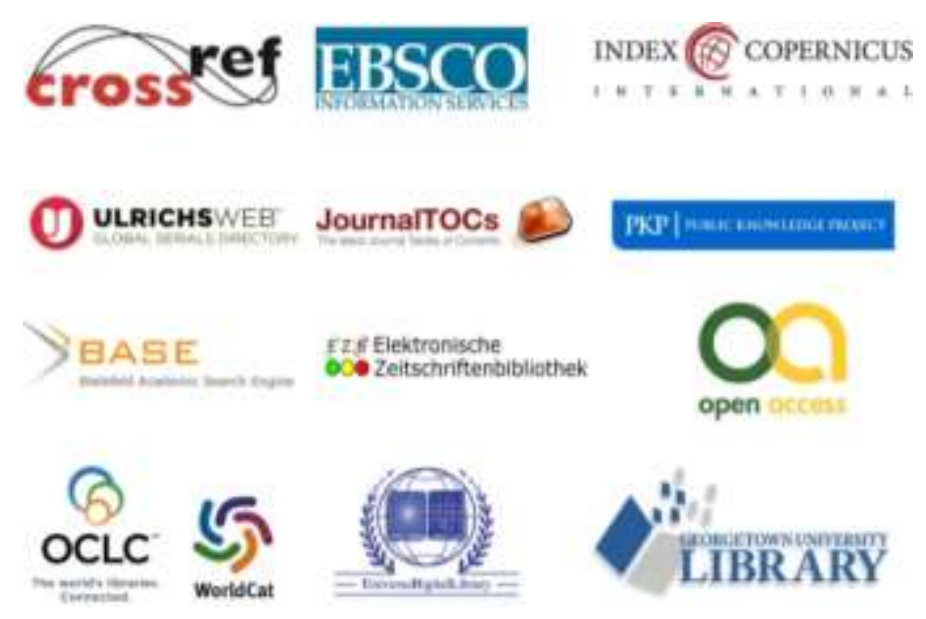

